\title{
Difusão de plantas alimentícias não convencionais através de ferramentas inovadoras
}

\section{Diffusion of non-conventional food plants through innovative tools}

\section{Difusión de plantas de alimentos no convencionales mediante herramientas inovadoras}

Recebido: 17/03/2021 | Revisado: 23/03/2021 | Aceito: 29/03/2021 | Publicado: 06/04/2021

Tadeu Patêlo Barbosa

ORCID: https://orcid.org/0000-0002-7688-6093 Instituto Federal de Educação, Ciência e Tecnologia de Alagoas, Brasil E-mail: tadeupbarbosa@gmail.com

Jadson Adyel Santos Lins

ORCID: https://orcid.org/0000-0002-2648-9284 Universidade Federal de Alagoas, Brasil

E-mail: jadsonlins.g3@gmail.com

Geane Maria da silva

ORCID: https://orcid.org/0000-0001-5094-0816

Instituto Federal de Educação, Ciência e Tecnologia de Alagoas, Brasil

E-mail: geaneifal@gmail.com

Ellen Carine Neves Valente

ORCID: https://orcid.org/0000-0002-3839-4856

Universidade Federal de Alagoas, Brasil

E-mail: ellencvalente@yahoo.com.br

André Suêldo Tavares de Lima

ORCID: https://orcid.org/0000-0003-4687-0645

Instituto Federal de Educação, Ciência e Tecnologia de Alagoas, Brasil

E-mail: andre.sueldo@ifal.edu.br

\begin{abstract}
Resumo
As plantas alimentícias não convencionais (PANC) são aquelas com distribuição limitada, restringidas a determinadas localidades, tendo grande peso na alimentação e na cultura de populações tradicionais. Essas PANC estão entre as fontes de alimentos que se desenvolvem em ambientes naturais sem a necessidade de insumos e da derrubada de novas áreas, porém embora disponíveis a um custo baixo, ainda são desconhecidas e subutilizadas por uma parcela significativa da população. O presente trabalho objetivou desenvolver produtos educacionais no formato de cartilha e aplicativo para dispositivo móvel para divulgação de PANC em oficinas e dias de campos com estudantes do curso de agroecologia e agricultores. Os produtos educacionais - uma cartilha e um aplicativo para dispositivos móveis, o "Info PANC" - foram bem recebidos e bem avaliados pelos usuários. O propósito das oficinas foi atingido, já que a degustação dos preparos culinários atraiu os ouvintes, que elogiaram os pratos e as informações compartilhadas.
\end{abstract}

Palavras-chave: Soberania alimentar; Biodiversidade; Agroecologia; Cartilha educacional; Aplicativo para dispositivos móveis.

\begin{abstract}
Non-conventional food plants (PANC) are those with limited distribution, restricted to certain locations, having great weight in the food and culture of traditional populations. These PANCs are among the sources of food that develop in natural environments without the need for inputs and the felling of new areas, but although available at a low cost, they are still unknown and underutilized by a significant portion of the population. The present work aimed to develop educational products in the format of a booklet and application for a mobile device for the dissemination of PANC in workshops and field days with students of the agroecology course and farmers. Educational products - a booklet and an application for mobile devices, the "Info PANC" - were well received and well evaluated by users. The purpose of the workshops was achieved, as the tasting of culinary preparations attracted listeners, who praised the dishes and shared information.
\end{abstract}

Keywords: Food sovereignty; Biodiversity; Agroecology; Educational booklet; Application for mobile devices.

\section{Resumen}

Las plantas alimenticias no convencionales (PANC) son aquellas de distribución limitada, restringidas a determinadas localizaciones, que tienen un gran peso en la alimentación y cultura de poblaciones tradicionales. Estos PANC se encuentran entre las fuentes de alimentos que se desarrollan en ambientes naturales sin la necesidad de insumos y la tala de nuevas áreas, pero aunque están disponibles a bajo costo, aún son desconocidos y subutilizados por una parte importante de la población. El presente trabajo tuvo como objetivo desarrollar productos educativos en formato de cuadernillo y aplicación para dispositivo móvil para la difusión de PANC en talleres y jornadas de campo con estudiantes del curso de agroecología y agricultores. Los productos educativos, un folleto y una aplicación para 
dispositivos móviles, el "Info PANC", fueron bien recibidos y bien evaluados por los usuarios. El propósito de los talleres se logró, ya que la degustación de preparaciones culinarias atrajo a los oyentes, quienes elogiaron los platos y compartieron información.

Palabras clave: Soberanía alimentaria; Biodiversidad; Agroecología; Folleto educativo; Aplicación para dispositivos móviles.

\section{Introdução}

O pioneiro nos estudos e divulgação das Plantas Alimentícias Não Convencionais (PANC) na América do Sul foi o professor argentino Eduardo Hugo Rapoport. Nesse momento inicial, as plantas não convencionais possuíam as denominações "malezas comestibles", "yuyos", "plantas nativas comestibles" e "plantas silvestres comestibles" (Kinupp \& Lorenzi, 2014)

As plantas alimentícias não convencionais (PANC) estão entre as fontes de alimentos que se desenvolvem em ambientes naturais sem a necessidade de insumos e da derrubada de novas áreas (Bressan et al., 2011). Porém, muitas dessas plantas, embora disponíveis a um custo baixo, ainda são desconhecidas e subutilizadas por uma parcela significativa da população (Kinupp, 2007).

De acordo com Kelen et al. (2015), atualmente, existe uma necessidade urgente da promoção de mutualidade entre o conhecimento científico e o popular, junto com a busca de uma maior integração entre a economia e a biodiversidade, promovendo a conservação e a sustentabilidade dos nossos biomas.

Dessa forma, o resgate e a valorização na alimentação diária dessas espécies não convencionais representam ganhos significativos do ponto de vista cultural, econômico, social e nutricional, considerando a tradição no cultivo por várias comunidades (Kinupp \& Lorenzi, 2014).

A preocupação da humanidade com uma melhor alimentação é um fenômeno relativamente recente. Quando se fala no resgate da utilização de plantas que não são comuns na alimentação diária, mas que possuem bons valores nutricionais e que não são necessários grandes tratos culturais para o desenvolvimento dessas espécies, isso se torna algo ainda mais recente.

No estado de Alagoas, estudos nessa área são raros, e por essa razão são extremamente necessários para a modificação desse cenário, possibilitando assim o auxílio no desenvolvimento da soberania alimentar, principalmente para as populações mais carentes. Logo, é necessário tornar atrativo o consumo das PANC pela população em geral, criando o interesse nesse tema.

Em conjunto, soluções tecnológicas voltadas para a agricultura vêm sendo destaque nos últimos anos, já que promovem, dentre outras coisas, a economia de recursos, como é o caso de técnicas mais modernas na irrigação, que resultam em menor gasto de água durante o ciclo produtivo das diversas culturas. Nesse sentido, a criação de produtos educacionais que estreitem a relação da tecnologia com a cultura do campo, de fácil entendimento e utilização pelos usuários, e que promovam a cooperação, pode ser um dos melhores aliados.

A Organização das Nações Unidas para a Educação, Ciência e Cultura [UNESCO] (2014) define a aprendizagem móvel como aquela que envolve o uso de tecnologias móveis, isoladamente ou em combinação com outras tecnologias de informação e comunicação (TIC), a fim de permitir a aprendizagem a qualquer hora e em qualquer lugar.

Nas últimas décadas do século 20, vivenciou-se de forma intensiva a inserção das TIC em diferentes setores sociais. Estas tecnologias potencializaram novas formas de comunicação, de aprendizagem, de disseminação de conteúdos e de culturas digitais. A primeira década do século 21 é marcada por outra transformação tecnológica causada pela frequente utilização das tecnologias móveis conectadas em redes (lucena, 2016).

Os tablets, notebooks, smartphones e outros dispositivos móveis têm possibilitado uma comunicação desprendida de lugares fixos e que utiliza diferentes linguagens e novos processos sociotécnicos próprios deste novo ambiente informacional e da cultura da mobilidade. Já no espaço escolar, a inserção das TIC foi intensificada a partir de 1997, principalmente por conta 
de políticas públicas que vêm priorizando a criação de setores de informática nas escolas, uso de notebooks, tablets e lousas digitais (Lucena, 2016).

Em adição, Nietsche et al. (2012) afirmam que o uso de tecnologias no processo de ensino e aprendizagem em ações de educação em saúde facilita a participação da comunidade, desde que tenha como pressuposto atender alguma necessidade daquele povo, levando o indivíduo a pensar, refletir, agir, transformando-o assim em sujeito ativo no próprio processo de desenvolvimento.

Oliveira e Alencar (2017) afirmam que a conjuntura atual na prática de ensino é de uma educação fortemente digital, focada no aluno e de maneira interativa e colaborativa. Os nativos digitais são atores ativos no quadro educacional, que vai desde o ensino básico até o ambiente universitário. A geração móvel de alunos, ou mais popularmente chamada "geração polegar" necessita de planos curriculares que incentivem o uso de tecnologias móveis para aprendizagem e aquisição de conhecimento.

Pontes et al. (2017) desenvolveram um aplicativo para dispositivos móveis visando auxiliar na educação financeira, o qual foi testado com um grupo de crianças do ensino fundamental, na faixa etária entre 8 e 12 anos, em uma escola pública municipal em Salto/SP. A maioria dos usuários assentiu que o aplicativo foi relevante no propósito de auxiliar no aprendizado de melhores práticas financeiras.

Já Oliveira e Alencar (2017) relataram a experiência no uso de aplicativos móveis como ferramenta para obtenção de informação e educação na área de saúde, principalmente de Medicina. As novas tecnologias de informação e comunicação utilizadas por meio de dispositivos móveis são atualmente o grande trunfo para uma renovação do contexto educacional com objetivo de favorecer uma geração de alunos que nasceu literalmente conectada à tecnologia.

Mesmo diante das tecnologias móveis, o uso de materiais impressos ainda continua tendo algum valor, principalmente com pessoas mais idosas ou mais carentes. Nesse sentido, Viana et al. (2018) desenvolveram uma cartilha denominada "Alimentação Complementar da criança de 06 a 12 meses: O que é importante saber", com o intuito de auxiliar na educação sobre o tema, e inferiram que esse tipo de abordagem pode contribuir na educação em saúde, principalmente quando se relaciona à promoção da saúde alimentar de populações das regiões que necessitam melhorar indicadores de saúde relacionados a saúde da criança.

Estes trabalho teve como objetivos; Elaborar e distribuir uma cartilha educacional contendo informações e sugestões culinárias das principais PANC encontradas nos assentamentos e feiras; Criar um aplicativo educacional para dispositivos móveis com localização de estabelecimentos que comercializam PANC e contendo informações e sugestões culinárias das principais PANC encontradas nos assentamentos e feiras; Realizar oficinas em escolas e assentamentos da reforma agrária, focando na utilização da cartilha e do aplicativo, bem como degustação de alguns preparos culinários contendo PANC.

\section{Metodologia}

A presente pesquisa científica, no que diz respeito a sua finalidade, foi do tipo aplicada, voltada para a aquisição de conhecimento empírico, adquirido através das experiências relatadas pelos participantes.

Quanto ao objetivo, foi uma pesquisa descritiva, que apresentou abordagem tanto de aspectos quantitativos como de aspectos qualitativos. Com relação aos procedimentos de coleta da informação, foram realizadas a pesquisa bibliográfica, estudo de caso e pesquisa de campo.

O tipo de pesquisa qualitativa utilizado no trabalho foi a pesquisa-ação, conforme descrito por Baldissera (2001), consistindo em obter os dados nas próprias comunidades avaliadas, valorizando o saber e a prática diária dos entrevistados, buscando por soluções para determinadas questões locais, unindo assim a ciência com mudanças positivas para a realidade de vida dessas comunidades. 
Todos os participantes assinaram termo de consentimento livre e esclarecido o qual declarava aceitar participar por sua própria vontade, sem receber qualquer incentivo financeiro ou ter qualquer ônus e com a finalidade exclusiva de colaborar para o sucesso da pesquisa. O pesquisado também foi informado(a) dos objetivos estritamente acadêmicos do estudo e que sua colaboração se faria de forma anônima.

A pesquisa foi realizada com estudantes do Ifal, Campus Maragogi e agricultores do Assentamento Nova Jerusalém no município de Maragogi. A escolha por essa comunidades foi pelo fato de já apresentarem relatos de consumo de PANC pela sua população, o que permitiu analisar as espécies que ocorrem na região.

A identificação das espécies foi feita durante as visitas de campo, juntamente com os moradores dos assentamentos, os quais identificaram as plantas que ocorriam na localidade através de seus respectivos nomes populares. Também foram feitos registros fotográficos.

Para identificação de nome científico e demais aspectos, utilizou-se o Guia de identificação, aspectos nutricionais e receitas ilustradas de PANC, obra de Kinupp e Lorenzi (2014).

Após a correta identificação, além das demais informações disponíveis no Guia mencionado, buscou-se na literatura científica estudos relacionados a determinadas espécies, visando os aspectos nutricionais, de uso geral e culinário.

Considerando que os moradores dos assentamentos são pessoas predominantemente de baixo poder aquisitivo, sem acesso ou facilidade ao uso de tecnologias mais modernas, a criação de material em formato de cartilha impressa (e digital) vem com o propósito de possibilitar que os resultados obtidos cheguem também para esse conjunto de pessoas, buscando fornecer acesso ao conhecimento que os mesmos ajudaram a produzir.

A cartilha, que se encontra no endereço eletrônico do curso de mestrado profissional em tecnologias ambientais (PPGTEC) - Instituto Federal de Alagoas, Campus Marechal Deodoro "https://www2.ifal.edu.br/ppgtec/produtos-tecnicotecnologicos-ptts/arquivos/cartilha-panc_patelo-t.pdf", tem como conteúdo o nome popular da planta utilizada nas comunidades estudadas, o nome científico, os demais nomes populares, as informações sobre a espécie e as sugestões de usos culinários.

Ao todo foram selecionadas 11 espécies de PANC para a confecção da cartilha. A escolha foi feita a partir das espécies mais citadas na região, bem como aquelas mais predominantes e de maior importância nas comunidades, possibilitando assim a inclusão, de forma mais fácil e mais acessível, na alimentação do dia a dia dos próprios moradores.

Para validação dessa ferramenta educacional, foram impressas cópias físicas e distribuídas para moradores dos assentamentos na cidade de Maragogi, e para alunos do curso de Agroecologia no campus Maragogi/IFAL.

Além de atingir o público das comunidades, o material foi disponibilizado em bibliotecas e na página, pertencente ao grupo de pesquisa sobre PANC do campus Maragogi/IFAL, "pancs_maragogi” na rede social Instagram, possibilitando assim que outros interessados no tema possam obtê-la no futuro.

Buscando atingir uma maior parte da população em geral foi desenvolvimento um aplicativo para dispositivos móveis. O aplicativo contém um módulo informativo, contendo as seguintes informações de cada PANC: nome popular utilizado nas comunidades estudadas, nome científico, demais nomes populares, informações sobre a espécie e sugestões de usos culinários. Foram selecionadas as mesmas 11 espécies utilizadas na cartilha.

A aplicação utilizou tecnologias híbridas para o desenvolvimento, pois esse formato tem maior facilidade de portabilidade para as mais diversas plataformas, tal qual escolhida pela equipe Front-end de desenvolvimento (equipe responsável pela parte visual e de toda interação com o usuário), Ionic + Angular, na qual o aplicativo é desenvolvido como um SPA (Single Page App) consumindo toda base criada pelo Back-end (equipe responsável por banco de dados e lógica utilizada nas Interfaces de Programação de Aplicativos - API's), em que foi utilizado tecnologia Google, o Firebase, que é uma espécie de banco de dados (https://firebase.google.com). 
A utilização do Firebase basicamente tem duas versões, uma para alimentação dos dados por meio de um administrador, e outra para consumação dos dados (dentro do aplicativo).

O aplicativo foi lançado inicialmente para sistemas Android, sendo possível acessá-lo através da loja de aplicativos (Play Store) buscando pelo nome "Info PANC" ou baixado direto pelo link (https://play.google.com/store/apps/details?id=com.infopancs\&hl=pt_BR\&gl=US\&showAllReviews=true).

Para validação desse produto educacional, abriu-se um formulário de pesquisa online na plataforma "Google Forms", em que foram realizadas algumas perguntas aos usuários, visando identificar a experiência no uso e assim buscar melhorias.

Foram realizadas oficinas no campus Maragogi/IFAL, com alunos do curso de Agroecologia e hospedagem e com alguns agricultores moradores do Assentamento Nova Jerusalém. Nessas oficinas foram apresentados a cartilha e aplicativo, além de serem distribuídas as cartilhas e as informações para a utilização do aplicativo "Info PANC". Também foi realizada degustação com alguns preparos culinários contendo as PANC.

\section{Resultados e Discussão}

Ao todo foram realizadas quatro oficinas, uma com os moradores do Assentamento Nova Jerusalém e três com turmas de alunos do curso de Agroecologia do campus Maragogi/IFAL. Para a oficina no assentamento Nova Jerusalém foram entregues convites na casa dos moradores.

$\mathrm{Na}$ oficina realizada no assentamento Nova Jerusalém, cada convidado ao chegar recebeu um exemplar da cartilha "Receitas com Plantas Alimentícias Não Convencionais (PANC) - Plantas encontradas em assentamentos no estado de Alagoas, nos municípios de Murici e Maragogi” (Figura 1). Em seguida, proferiu-se uma breve explicação sobre o significado das PANC, e logo após foram degustados alguns preparos culinários com essas espécies.

Como se trata de uma população mais carente e geralmente de idade mais avançada, o uso de tecnologias mais modernas pode acabar se tornando uma barreira. Por essa razão, é importante a distribuição de material adequado ao públicoalvo, que auxilie na didática, pois permite que o ouvinte leve o material para casa, ajudando na consolidação do conhecimento abordado durante a atividade.

Nessa perspectiva, Reis et al. (2012) relataram sobre a importância da utilização de materiais didáticos como a cartilha, servindo de ferramenta auxiliar na educação ambiental. Os autores destacam que a cartilha produzida por eles estimulou os usuários (alunos de escolas municipais em Cruz das Almas/BA) a buscarem por uma melhor compreensão do ambiente em que vivem, relacionando o que estudam na teoria com a sua importância na vida cotidiana, assim proporcionando uma melhor compreensão do ambiente em que vivem, e sua responsabilidade na transformação do mesmo, desenvolvendo senso crítico e buscando atitudes que minimizem os problemas relacionados. 
Figura 1. Oficina de preparos culinários com PANC feita com moradores do assentamento Nova Jerusalém (Maragogi/AL).

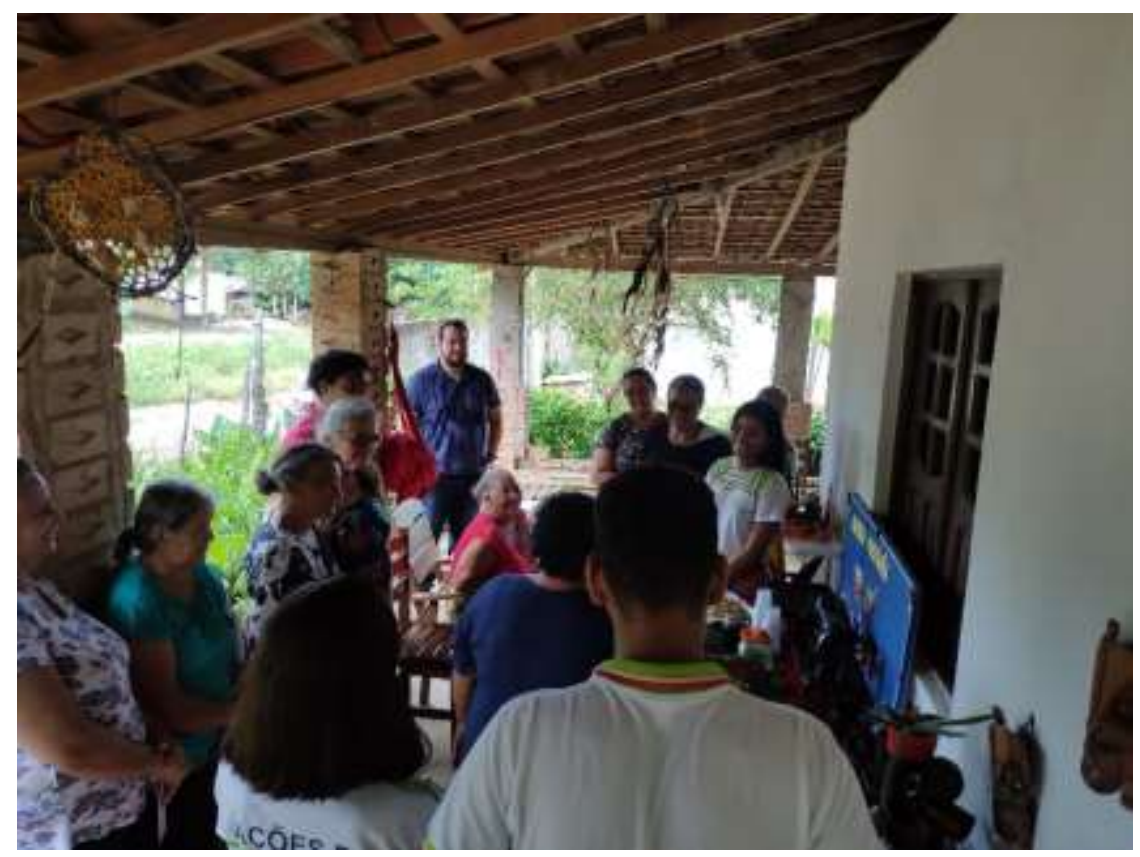

Fonte: Autores.

A Figura 2 apresenta os pratos servidos na oficina no assentamento Nova Jerusalém foram: salada crua com brotos da folha de seriguela (Spondias purpurea), hortelã grande/grosso (Plectranthus amboinicus) e folhas de batata-doce (Ipomoea batatas); coração/mangará da bananeira e casca de banana (Musa × paradisiaca) refogados com verduras e temperos; chips de banana verde; suco das folhas de seriguela com um toque de limão; e geleia feita com pétalas de papoula/hibisco (Hibiscus rosa-sinensis). Os alimentos foram servidos em folha de bananeira.

Figura 2. Mesa com preparos culinários contendo PANC.

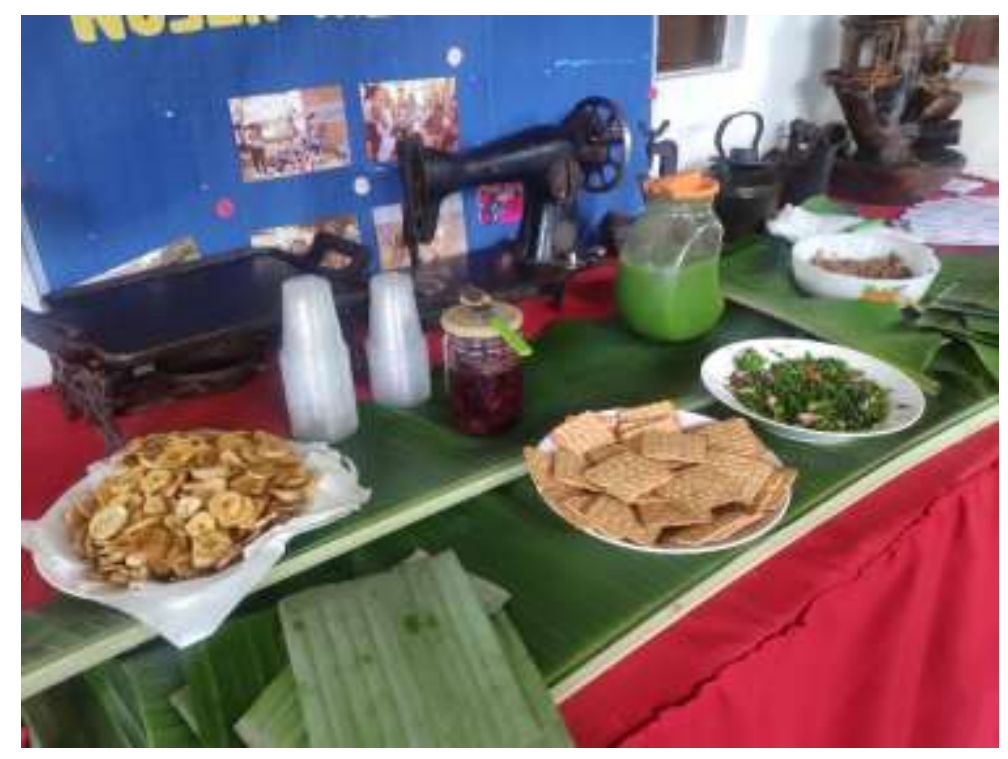

Fonte: Autores.

Percebe-se que todos os participantes da oficina foram mulheres, majoritariamente com idade acima de 55 anos. Em consonância, Barreira et al. (2015), ao realizarem levantamento sobre a ocorrência de PANC na zona rural de Viçosa/MG, identificaram que os idosos são os maiores conhecedores das formas de uso, épocas de frutificação, ambiente de propagação, 
dentre outras utilidades das PANC. O quintal produtivo pode ser considerado uma alternativa de atividade produtiva para os idosos, auxiliando na ocupação destes. Além disso, esse fator ressalta a importância de tentar despertar o interesse dos jovens, para que esse tipo de cultura não possa acabar se perdendo. Estudo feito por Bezerra e Santos Filho (2021) informam que pesquisas relacionadas a plantas alimentícias não convencionais ainda são incipientes.

Durante toda a oficina as ouvintes demonstravam interesse, sempre comentando que conheciam alguma espécie, que já tinham consumido ou que não sabiam que podiam comer aquela determinada planta que ocorria ali no local em que residem. Isso demonstra a importância de um suporte teórico e técnico quando visamos a mudança na perspectiva relacionada as temáticas agroecológicas.

Corroborando com essa questão, Teixeira e Pires (2017), ao analisarem os sistemas de produção de base agroecológica familiar diante da estiagem prolongada no semiárido nordestino, destacaram a importância da assessoria técnica para a alavancagem do processo de transição agroecológica.

Ao provar o refogado de coração da bananeira e casca da banana, algumas moradoras disseram que sentiram gosto de frango, e que se não tivessem sido avisadas achariam que seria essa proteína de origem animal. No geral, para se tornarem próprias e atrativas para consumo, as PANC precisam de preparo culinário simples, como refogar, branquear (colocar rapidamente em água fervente), etc. O coração da bananeira, por exemplo, precisa ser escaldado algumas vezes para retirar o sabor característico de amargo que possui.

Kinupp e Lorenzi (2014) acrescentam que é possível o uso do coração da bananeira em um refogado, mas sendo necessário deixar em água com sal e suco de limão para minimizar a oxidação.

A geleia de hibisco (Figura 3) servida como sobremesa tem um preparo rápido, cerca de 8 a 10 minutos, e simples, levando apenas as pétalas da flor, água e açúcar. Pode ser bem versátil nos sabores ao se acrescentar especiarias, como canela ou cravo, tornando o sabor mais atrativo.

Um pote grande de geleia, aproximadamente $350 \mathrm{~g}$, com essa PANC tem um custo menor que $\mathrm{R} \$ 3,00$, enquanto um pote de geleia no supermercado custa em torno de $\mathrm{R} \$ 10,00$. Essa flor é abundante nos locais estudados, e por essa razão, após o processamento, os assentados poderiam comercializar esse doce, o que geraria um complemento para a renda familiar.

Figura 3: Geleia feita com pétalas de Hibisco ou Papoula (Hibiscus rosa-sinensis).

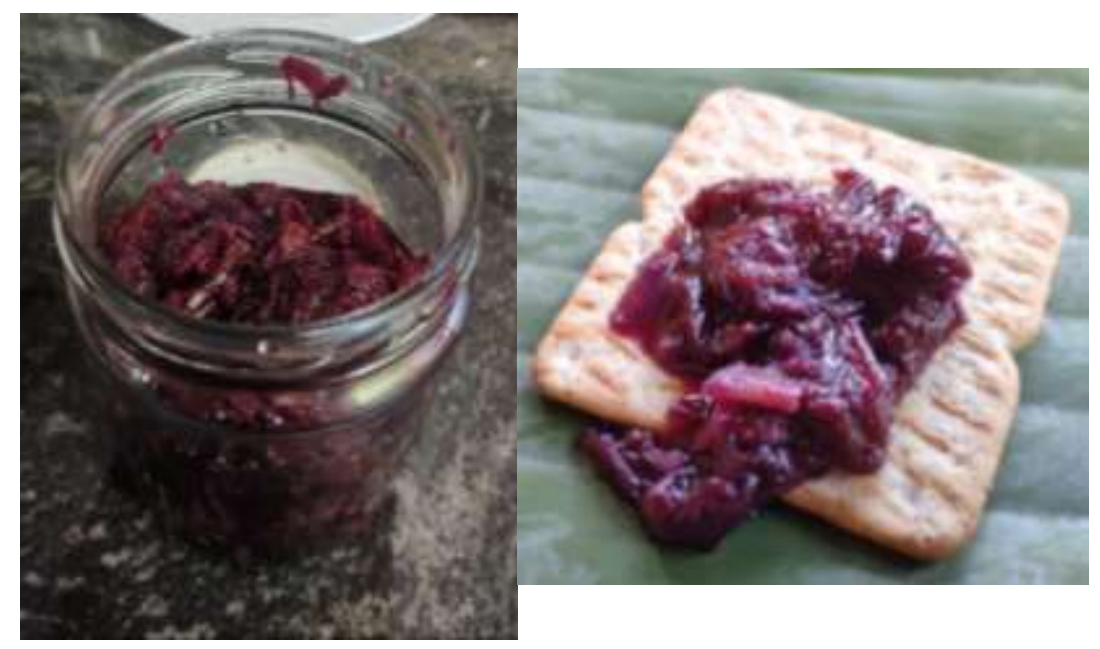

Fonte: Autores.

Nesse sentido, Gollner-Reis et al. (2016) fabricaram doces desenvolvendo tecnologias para o aproveitamento integral de alimentos (TAIA), juntamente com moradores dos assentamentos da reforma agrária Dom Hélder Câmara, situado em 
Murici/AL e Flor da Serra, situado em Joaquim Gomes/AL. Foram fabricados doces a partir da casca da banana (brigadeiro), casca da abóbora, casca do mamão verde, dentre outros.

Ao fim da oficina no assentamento Nova Jerusalém, as participantes foram questionadas sobre o que acharam dos conhecimentos repassados, e todas sinalizaram que gostaram, comentando que não sabiam que podiam utilizar na alimentação algumas plantas que elas têm ao alcance facilmente. Indicaram também que gostaram das informações divulgadas na cartilha educacional, e que iriam fazer as receitas em casa. Nas oficinas com os estudantes do curso de Agroecologia também ocorreu degustação (Figura 4), mas apenas da geleia de papoula.

Figura 4. Degustação de geleia de papoula (Hibiscus rosa-sinensis) pelos alunos do curso de Agroecologia do campus Maragogi/IFAL.

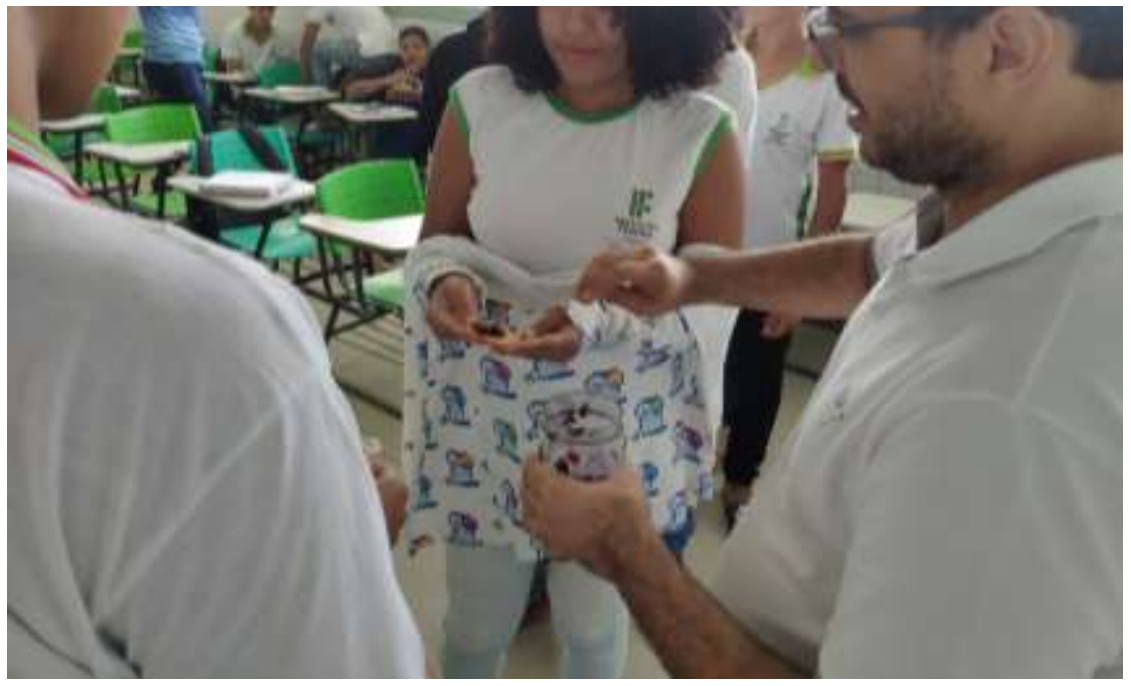

Fonte: Autores.

Nas três oficinas com as turmas de agroecologia foi realizada uma apresentação com informações gerais sobre as PANC, e após deu-se enfoque ao uso do aplicativo, solicitando que os alunos instalassem em seu dispositivo e, em seguida, avaliassem a experiência através do formulário online de pesquisa.

As informações do aplicativo foram pensadas para atrair o público em geral, assim buscou-se colocar informações em uma linguagem objetiva e de fácil entendimento (Figura 5). Conforme Bonifácio et al. (2012), quem utiliza aplicativos em dispositivos móveis, seja para trabalho, estudo ou lazer, geralmente busca uma solução prática e rápida, tendo como critério principal a facilidade de acesso à informação em qualquer lugar e a qualquer hora.

Valentim et al. (2014) relatam a importância de incentivar a indústria de software a realizar avaliações de usabilidade com maior frequência durante o desenvolvimento do produto, pois este é um meio eficaz para se identificar problemas e melhorar o aplicativo antes de ser lançado no mercado.

Durante a oficina, os alunos demonstraram surpresa em saber que algumas das muitas plantas próximas a eles podem servir de alimento com o devido preparo culinário. 
Figura 5. Capturas de tela do aplicativo para dispositivos móveis "Info PANC".

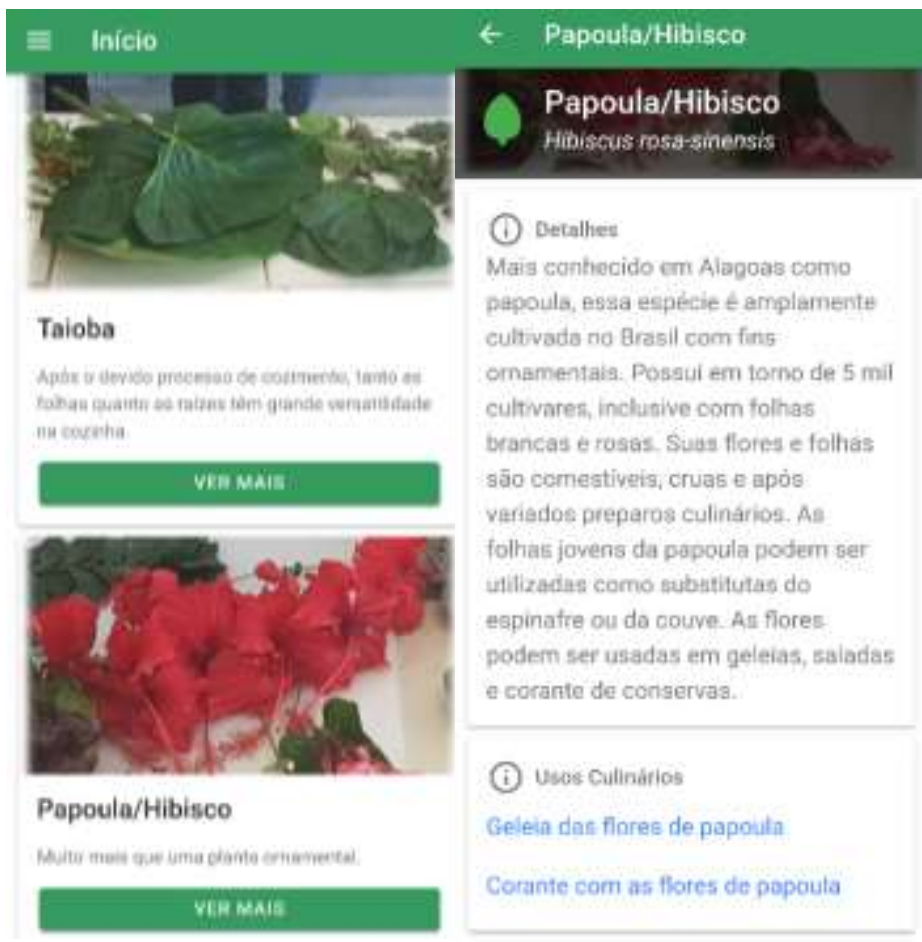

Fonte: Autores.

Além dos alunos, o formulário de pesquisa online também foi disponibilizado para alguns grupos de potencial interesse relacionado às PANC. No total foram obtidas 42 respostas. 90,5\% sinalizaram que as informações disponibilizadas no aplicativo foram suficientes para despertar o interesse em consumir as PANC; 85,7\% sentiram interesse em utilizar as PANC em algum preparo culinário; e 69\% acharam suficientes as informações disponibilizadas.

Dias et al. (2013) reforçam a importância no uso de dispositivo móveis na educação de jovens adultos, devendo focar no aprendizado personalizado, que tem o estudante como principal interagente do processo, numa perspectiva participativa e de colaboração, possibilitando visita livre às informações de interesse em tempos e espaços variados, conforme necessidade particular e a construção de suas identidades.

Levando em consideração que o objetivo do aplicativo é atingir o público em geral, os resultados podem ser considerados promissores. No futuro, pode-se acrescentar mais espécies de PANC, além de aumentar a quantidade de informações. Nas sugestões de usos culinários, pode-se acrescentar mais receitas, além de adicionar fotos dos pratos prontos, o que tornaria ainda mais atrativo para os usuários.

Em seguida, os alunos do curso de Agroecologia foram convidados a conhecer algumas PANC presentes no próprio campus Maragogi. Foram observados o mangará da bananeira (Figura 6), o feijão guandu (Cajanus cajan) e a Moringa oleifera). Foram reforçadas algumas explicações sobre essas espécies. Foi observado perceber que no local do plantio de bananeira havia no chão restos do coração. Segundo Castro et al. (2021) é necessária a utilização de metodologias nas escolas que visem à valorização das vivências, saberes, interesses e curiosidades dos alunos acerca da natureza. 
Figura 6. Explicações sobre o coração da bananeira em plantação existente no campus Maragogi/IFAL.

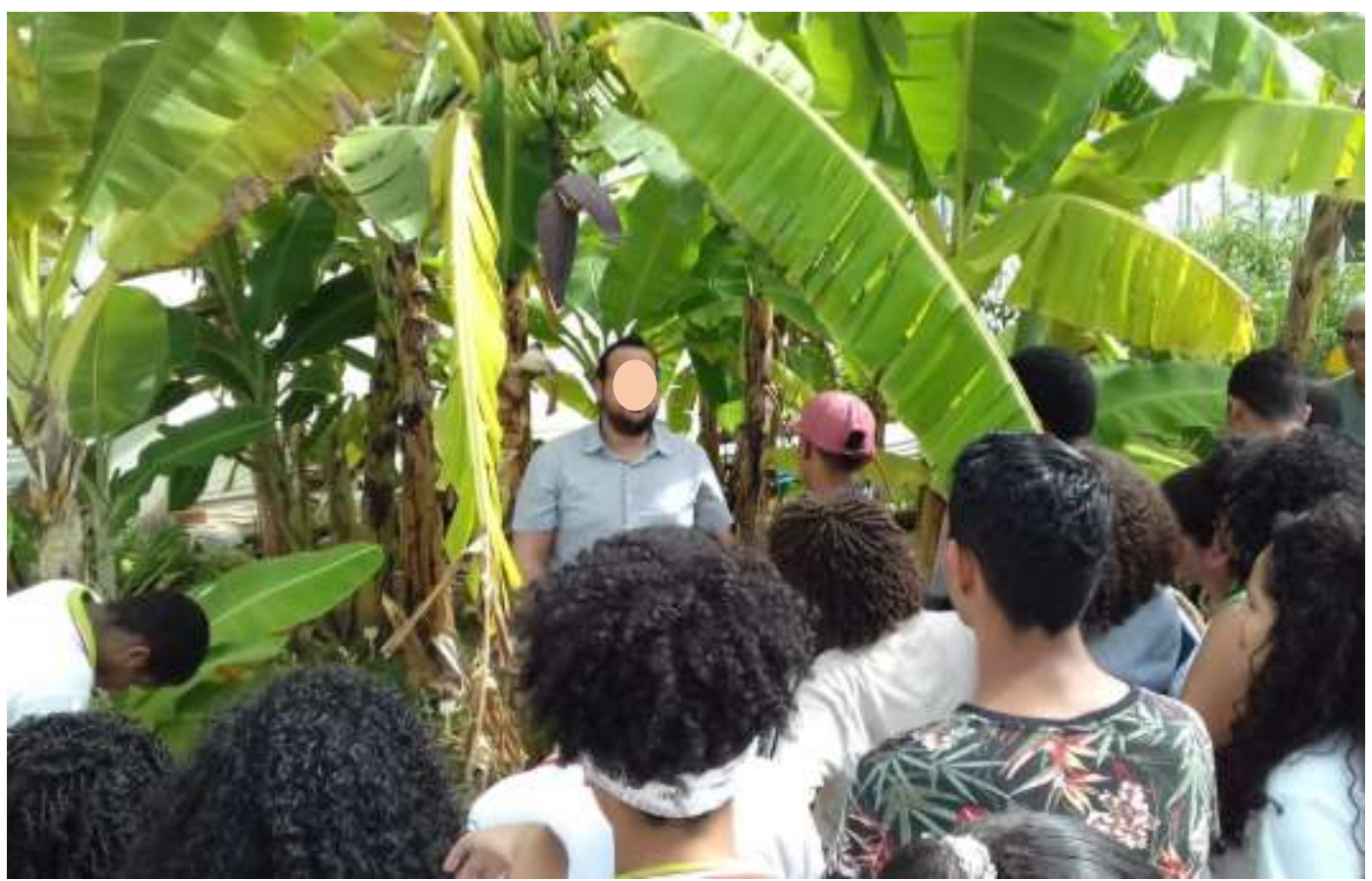

Fonte: Autores.

Ao finalizar essa atividade, foi feita uma rápida pesquisa de avaliação oral com os alunos sobre o conteúdo abordado.

Todos sinalizaram que estavam satisfeitos ou muito satisfeitos com o conhecimento que estava sendo repassado.

\section{Considerações Finais}

A cartilha produzida foi bem avaliada pelas moradoras que receberam-na no assentamento Nova Jerusalém (Maragogi/AL). Já o aplicativo "Info PANC" foi bem recebido pelos usuários do curso técnico. Isso indica a importância de divulgar resultados na linguagem adequada para aquele determinado público-alvo.

O propósito das oficinas foi atingido, já que a degustação dos preparos culinários atraiu os ouvintes, que elogiaram os pratos e as informações compartilhadas.

As ferramentas inovadoras que foram produto dessa pesquisa têm grande valor por estarem adaptadas ao público-alvo. A cartilha educacional fica mais fácil de ser acessada por pessoas com idade mais avançada ou de baixo poder aquisitivo. Já o aplicativo educacional ficou mais voltado para o público jovem e com mais facilidade de acesso as tecnologias mais modernas. Por essa razão, reforça-se a necessidade dessa adaptação da linguagem científica para uma linguagem própria para divulgação ao público em geral.

\section{Agradecimentos}

A equipe técnica deste trabalho agradece a todos os participantes do projeto PANC em Maragogi.

\section{Referências}

Baldissera, A. (2001). Pesquisa-Ação: Uma metodologia do "conhecer" e do "agir" coletivo. Revista Sociedade em Debate. Universidade Católica de Pelotas, $7(2), 5-25$.

Barreira, T. F., Paula Filho, G. X., Rodrigues, V. C. C, Andrade, F. M. C., Santos, R. H. S., Priore, S. E. \& Pinheiro-Sant'ana, H. M. (2015). Diversidade e equitabilidade de Plantas Alimentícias Não Convencionais na zona rural de Viçosa, Minas Gerais, Brasil. Revista Brasileira de Plantas Medicinais (RBPM), Campinas, 17(4), 964-974. 
Bezerra, M. A., \& Santos Filho, F. S. (2021). Alimentos florestais aquáticos: prospecção científica do potencial nutricional negligenciado. Pesquisa, Sociedade e Desenvolvimento, 10, (3), e32510313457, 10.33448 / rsd-v10i3.13457. https://rsdjournal.org/index.php/rsd/article/view/13457.

Bonifácio, B., Fernandes, P., Santos, F., Oliveira, H. \& Conte, T. (2012). Usabilidade de Aplicações Web Móvel: Avaliando uma Nova Abordagem de Inspeção através de Estudos Experimentais. Congresso Ibero-Americano em Engenharia de Software (CIbSE), 236-249.

Bressan, R. A., Reddy, M. P., Chung, S. H., Yun, D. J., Hardin, L. S. \& Bohnert, H. J. (2011). Stress-adapted extremophiles provide energy without interference with food production. Food Security, 3, (1), 93-105.

Castro, M. A., Bonilla, O. H.,Pantoja, L. D. M., Mendes, R. M. S., Edson-Chaves, B. \& Lucena, E. M. P.Conhecimento etnobotânico dos alunos de Ensino Médio sobre plantas medicinais em Maranguape-Ceará. Research, Society and Development, 10, (3), e8910313008, 2021. 10.33448/rsd-v10i3.13008.

Dias, D. S. F., Deus, M. M. M. \& Ireland, T. D. (2013). A contribuição do uso de dispositivos móveis para um currículo voltado a uma educação transformadora na EJA. Revista Espaço do Currículo, 6(2), 280-291.

Gollner-Reis, K. T. M., Silva, M. H., Silva, M. A., Barbosa, K. K. S. \& Gollner-Reis, J. P. (2016). Desenvolvimento de tecnologias de fabricação de doces e geleias como tecnologias do aproveitamento integral (TAIA) de frutas, hortaliças e de plantas comestíveis não convencionais (PANCs). Anais do Congresso Nacional de Pesquisa e Ensino em Ciências. Campina Grande-PB, Realiza Editora. https://www.editorarealize.com.br/editora/anais/conapesc/2016/TRABALHO_EV058_MD4_SA80_ID764_30042016205857.pdf

Kelen, M. E. B., Nouhuys, I. S. V., Kehl, L. C., Brack, P.\& Silva, D. B. (2015). Plantas Alimentícias Não Convencionais (PANCs) - Hortaliças Espontâneas e Nativas. (1 ${ }^{\mathrm{a}}$ edição), Porto Alegre: UFRGS, 44.

Kinupp, V. F. \& Lorenzi, H. (2014). Plantas Alimentícias Não Convencionais (PANC) no Brasil: guia de identificação, aspectos nutricionais e receitas ilustradas. Nova Odessa: Instituto Plantarum de Estudos da Flora, 768.

Kinupp, V. F. (2007). Plantas Alimentícias Não Convencionais da Região Metropolitana de Porto Alegre, RS. (Tese de Doutorado) Programa de PósGraduação em Fitotecnia da Faculdade de Agronomia, Universidade Federal do Rio Grande do Sul, Porto Alegre, Rio Grande do Sul, Brasil.

Lucena, S. (2016). Culturas digitais e tecnologias móveis na educação. Educar em Revista, Curitiba, 59, 277-290.

Nietsche, E. A., Lima, M. G. R., Rodrigues, M. G. S., Teixeira, J. A., Oliveira, B. N. B., Motta, C. A., Gribler, C. S., Gribler, V. M., Lucas, D. D. I. \& Farias, M. K. F.(2012). Tecnologias inovadoras do cuidado em enfermagem. Revista de Enfermagem da UFSM, 2, 182-189.

Oliveira, A. R. F. \& Alencar, M. S. M. (2017). O uso de aplicativos de saúde para dispositivos móveis como fontes de informação e educação em saúde. Revista Digital Biblioteconomia e Ciência da Informação, v15, (1), 234-245.

Pontes, A. N., Tomazela, M. G. J. M. \& Alves, D. C.(2017). Nico: Aplicativo para auxiliar na educação financeira de crianças do ensino fundamental. Revista FATEC Zona Sul, 4, (1).

Reis, V. R., Santos, A. S., Machado, P. B.\& Souza, G. S. (2012) Utilização de cartilha como ferramenta de educação ambiental. Seminário Universidade Sociedade - Semana Kirimurê. Cachoeira/BA.

Teixeira, C. T. M. \& Pires, M. L. L. S. (2017). Análise da Relação Entre Produção Agroecológica, Resiliência e Reprodução Social da Agricultura Familiar no Sertão do Araripe. Revista de Economia e Sociologia Rural (RESR). Piracicaba-SP, 55, (1), 47-64.

Organização das Nações Unidas para a Educação, a Ciência e a Cultura. (2014). Diretrizes Políticas Para Aprendizagem Móvel. https://unesdoc.unesco.org/ark:/48223/pf0000227770. UNESCO.

Valentim, N. M. C., Rabelo, J., Silva, W., Coutinho, W., Mota, A. \& Conte, T. (2014). Avaliando a qualidade de um aplicativo web móvel através de um teste de usabilidade: um relato de experiência. XIII Simpósio Brasileiro de Qualidade de Software. Blumenau/SC.

Viana, L. R., Barreto, M. M., Girard, C. C. P. \& Teixeira, E.(2018). Tecnologia educacional para mediar práticas educativas sobre alimentação complementar na Amazônia: estudo de validação. Revista Ibérica de Sistemas e Tecnologias de Informação, 28. 